\title{
Energy information engagement among the poor: Predicting participation in a free workshop
}

\author{
Brian Southwell ${ }^{\mathrm{a}, \mathrm{b}, *}$, Kristina Ronneberg ${ }^{\mathrm{b}}$, Kelly Shen ${ }^{\mathrm{b}}$, Emily Jorgens ${ }^{\mathrm{b}}$, Juanita Hazel ${ }^{\mathrm{b}}$, \\ Rahiel Alemu ${ }^{\mathrm{b}}$, Jennifer Ross ${ }^{\mathrm{b}}$, Laura Richman ${ }^{\mathrm{b}}$, Daniel Vermeer ${ }^{\mathrm{b}}$ \\ a RTI International, Research Triangle Park, NC, United States \\ ${ }^{\mathrm{b}}$ Duke University, Durham, NC, United States
}

\section{A R T I C L E I N F O}

\section{Article history:}

Received 1 August 2014

Received in revised form 6 August 2014

Accepted 7 August 2014

\section{Keywords:}

Informal science education

Poverty

Social norms

Perceived understanding of energy

\begin{abstract}
A B S T R A C T
Although one option for increasing low-income consumer knowledge regarding household energy use is the development of free or low-cost educational workshops, exactly how to promote attendance for such workshops remains an open question. Here we briefly outline results from a set of in-depth interviews with applicants to the Low-Income Energy Assistance Program in Durham County, NC, USA. Models predicting intended attendance at workshops or community meetings suggested that factors such as utility costs, social norms, perceived ability to plan ahead, and perceived accessibility of energy information all matter more than one's general attitude toward energy workshop attendance. Many respondents expressed interest in energy education materials and faced challenging utility costs, but meeting attendance appears to be constrained by the everyday life obstacles of the poor.
\end{abstract}

(c) 2014 Elsevier Ltd. All rights reserved.
Social scientists are beginning to understand how the resource challenges that low-income populations face affect not only just their material standing but also the ways they are able to engage information, e.g., Bertrand et al. [6]. Those challenges, in turn, also likely constrain the success of educational programs charged with helping low-income consumers conserve energy at home. Scholars such as Moezzi and Janda [1] have called for increased attention to social context as we seek to understand building energy use, which suggests we need predictive models to assess information engagement among low-income populations that include contextual factors, such as personal circumstances and social norms, as well as perceptions of one's ability to digest information and plan ahead.

Exploration of how individual energy users make choices and interact with buildings is a central topic in this journal, e.g., Royston [2], Southwell and Murphy [3], Stern [4], Wallenborn and Wilhite [5], or Walker et al. [7]. Discussion of such decision-making often involves the possibility of consumer education interventions; specific focus on low-income audiences also introduces considerations of cost barriers that could reduce participation in training.

\footnotetext{
* Corresponding author at: RTI International, 3040 E. Cornwallis Road, PO Box 12194, Research Triangle Park, NC 27709, United States. Tel.: +1 9195418037.

E-mail addresses: bsouthwell@rti.org, brian.southwell@duke.edu (B. Southwell).

Although one option for increasing low-income consumer knowledge regarding household energy use is the development of free or low-cost educational workshops, exactly how to promote attendance for such workshops nonetheless remains an open question. To begin to address that question, here we briefly outline pilot results from a set of in-depth interviews with applicants to an energy assistance program for low income residents in Durham, NC (USA). We inquired about information needs, preferences, and tendencies. The interviews explored the time-orientation of residents, e.g., tendency toward immediate goals versus long-term goals, perceived social network norms regarding community energy education, and other factors.

\section{Methods}

We conducted face-to-face interviews $(n=61)$ with applicants to the Durham County, NC (USA), Department of Social Services Low-Income Energy Assistance Program. (We interviewed applicants separately from the application process and interviewees were not necessarily eligible for assistance.) Respondents received an LED flashlight for their time.

We focus in this brief on analysis of closed-ended items regarding participant intention to attend future energy workshops or meetings. To account for potential question order effects, we randomly assigned participants either to first to report future intention 
to attend a "free workshop" on household energy use if one was available near their home or to report intention to attend a "community meeting" on energy use. We then asked them about the alternately phrased option. We report data from both items as dependent measures separately.

We measured participant age, sex, household income, and average heating bill in recent months. We also measured attitude toward an energy use meeting or workshop (measured by two semantic differential items with useful/not useful and important/unimportant anchors), how many people one knows who attend such meetings or workshops (or descriptive norm), the extent to which important others think one should attend a meeting or workshop (or injunctive norm), one's sense of agency over future planning (measured by three items such as agreement that "I complete projects on time by making steady progress"), and perceived understanding of energy (i.e., agreement that "people like me" can understand energy).

\section{Results}

\subsection{Participant description}

Participants ranged in age from 24 to 78, with a median age of 43. They were mostly female (90\%) and African-American (96\%). Median annual household income was less than $\$ 20,000$ (US); $64 \%$ reported less than $\$ 20,000$ in annual household income. Most (87\%) rented their residence and nearly half of all participants lived in a freestanding house.

\subsection{Living experience}

The majority (57\%) of participants reported living in a home that was "drafty" most or all of the time during most recent winter. Most (75\%) also reported no weatherization had been done since they moved into the home. There was direct correspondence between income and energy inefficiency: those reporting less than $\$ 20,000$ (US) annual household income were more likely to live in a drafty home than those reporting more than $\$ 20,000$ (US) in income, $\chi^{2}=6.2, n=56, p<.05$.

\subsection{Reported interest in free energy workshops and predictors of future attendance}

The majority of respondents (74\%) agreed they would attend a free workshop or community meeting focused on household energy tips if one was available near their home. At same time, a majority (59\%) also reported attendance at such a meeting currently was somewhat uncommon or not at all common among people they knew.

We separately modeled intention to participate in a "free workshop" or a "community meeting" on energy use using all of the variables noted earlier. Slightly different models emerged for each type of meeting, although we also saw consistency in the types of predictors that emerged.

Our model of intention to attend a community meeting significantly added predictive value to a null model, $F(10,41)=3.1$, $p<.01, R^{2}=.43$. Significant predictors were future planning agency, beta $=.34, p<.05$, average heating bill, beta $=.53, p<.01$, and descriptive social norm for meeting attendance, beta $=.31, p<.05$. Community meeting attendance, in other words, was driven by utility costs, social norms, and one's own sense of being able to implement future plans. Our model of intention to attend a free workshop also significantly added predictive value, $F(10,41)=2.7$, $p<.05, R^{2}=.40$. Significant predictors for that model were simply average heating bill, beta $=.52, p<.01$, and perceived understanding of energy, beta $=.33, p<.05$. Attitude toward free energy workshops or meetings was not a significant predictor in either model, nor were demographic factors.

\section{Conclusion}

The low-income participants in our study reported considerable need for weatherization and expressed interest in receiving energy education. At the same time, however, predictive models of intended engagement with educational meetings suggested noteworthy constraints on meeting attendance. Although general attitude toward energy education workshops did not predict future attendance, personal circumstance, community norms, and perceived accessibility of energy information all played predictive roles. That suggests that simply urging low income populations to learn more about energy savings might not be the appropriate path, as many already express interest in household energy tips and recommendations. Future interventions to bolster household energy workshop attendance among the poor should consider assisting people with their everyday schedule management to facilitate attendance, highlighting those people in a community who do attend workshops as a way of shaping social norms, and portraying educational offerings as being accessible to all and not just the purview of experts.

\section{Acknowledgements}

The authors would like to thank other members of the team: Emily Conner, Drew Howard, and Sidharth Sharma. Sheree Knight and staff members with Durham County Social Services graciously facilitated data collection. Duke University's Bass Connections in Energy program funded this project and staff members of Duke's Energy Initiative were helpful, including Kyle Bradbury, David Doctor, Steve Hicks, and Richard Newell, as were Dan Curry and Ann Roy.

\section{References}

[1] Moezzi M, Janda KB. From if only to social potential in schemes to reduce building energy use. Energy Res Soc Sci 2014;1:30-40.

[2] Royston S. Dragon-breath and snow-melt: know-how, experience and heat flows in the home. Energy Res Soc Sci 2014;2:148-58.

[3] Southwell BG, Murphy J. Weatherization behavior and social context: the influences of factual knowledge and social interaction. Energy Res Soc Sci 2014;2:59-65.

[4] Stern PC. Individual and household interactions with energy systems: toward integrated understanding. Energy Res Soc Sci 2014;1:41-8.

[5] Wallenborn G, Wilhite H. Rethinking embodied knowledge and household consumption. Energy Res Soc Sci 2014;1:56-64.

[6] Bertrand M, Mullainathan S, Shafir E. Behavioral economics and marketing in aid of decision making among the poor. J Public Policy Mark 2006;25(1):8-23.

[7] Walker SL, Lowery D, Theobald K. Low-carbon retrofits in social housing: interaction with occupant behaviour. Energy Res Soc Sci 2014;2:102-14. 